\title{
Qualidade de sementes de soja colhidas de forma manual e mecânica com diferentes teores de água
}

\author{
Soybean seed quality, harvested by hand and mechanically, \\ with different levels of moisture content
}

\author{
Tereza Cristina de Carvalho ${ }^{1 *}$; Ana Dionísia da Luz Coelho Novembre ${ }^{2}$
}

\section{Resumo}

A colheita é uma das principais etapas no processo de produção de sementes de soja. O momento adequado para se efetuar a colheita pode variar em função do tipo de colheita e do grau de umidade das sementes. Neste sentido, o objetivo dessa pesquisa foi determinar as alterações fisiológicas de sementes de soja colhidas de forma manual e mecânica com diferentes teores de água. Para tanto, utilizaram-se sementes das cultivares Embrapa 48 e FTS Águia, que têm diferenças no teor de lignina do tegumento, colhidas de forma manual e mecanicamente com 18,0;15,0 e 12,0\% de água. Após a colheita, as sementes foram submetidas à secagem, e a qualidade das sementes foi avaliada pelos testes de germinação, emergência de plântulas, tetrazólio (viabilidade e vigor), envelhecimento acelerado e índice de velocidade de emergência de plântula. Em seguida, as sementes foram armazenadas $\left(20^{\circ} \mathrm{C}\right.$ e $45 \%$ UR do ar) e analisadas logo após a colheita e aos seis meses de armazenamento. Os resultados obtidos indicam que o parâmetro fisiológico das sementes de soja, não é afetado, quando: se realiza colheita manual com grau de umidade das sementes de $11,4 \%$ a $18,4 \%$; e para sementes colhidas à máquina, com grau de umidade entre $12,0 \%$ a 15,9\%; mantendo a qualidade fisiológica mesmo após seis meses de armazenamento.

Palavras-chave: Glycine max, viabilidade, vigor, armazenamento

\begin{abstract}
The harvest is one of the main steps in the production process of soybean seeds. The right time to harvesting can vary depending on the type of harvest and seeds moisture content. The goal of this research was to determine alterations in soybean seeds physiological, harvested with different levels of seed moisture content, by hand and mechanically. The soybean seeds were from cultivars Embrapa 48 and FTS Águia, which have differences in seed coat lignin content, harvested by hand and mechanically with the moisture contents of 18.0, 15.0 and $12.0 \%$. After harvest, the seeds were submitted to drying, and the seed quality was evaluated by germination, seedling emergence, tetrazolium (viability and vigor), accelerated aging tests and seedling speed of emergence. Then, seeds were kept in storage conditions $\left(20^{\circ} \mathrm{C}\right.$ and $\left.45 \% \mathrm{RU}\right)$ and analyzed soon after the harvest and at six months of storage. The results indicated that seed physiological potential, is not affected, when: harvested by hand with seeds moisture content of $11.4 \%$ to $18.4 \%$; and for seeds harvested mechanically, with moisture content between $12.0 \%$ to $15.9 \%$; maintaining physiological quality, even after the storage period.
\end{abstract}

Key words: Glycine max, viability, vigor, storage

\footnotetext{
${ }^{1}$ Enga Agr. ${ }^{\text {a }}$ M.Sc., Doutoranda em Agronomia, Produção Vegetal, Universidade Federal do Paraná, UFPR. Curitiba, PR. Bolsista da CAPES. E-mail: tcdcarva@gmail.com

${ }^{2}$ Prof. Associado, Dept ${ }^{\circ}$ de Produção Vegetal, Universidade de São Paulo, USP/ESALQ, Piracicaba, SP. E-mail: adlcnove@usp.br * Autor para correspondência
} 


\section{Introdução}

A soja (Glycine max) é uma das oleaginosas mais produzidas e consumidas no mundo. Segundo a Companhia Nacional do Abastecimento (CONAB, 2011), a produtividade da soja no Brasil para a safra 2010/2011 foi estimada em 68,6 milhões de toneladas, com área de produção de 24,1 milhões de hectares.

No entanto, sabe-se que a qualidade das sementes de soja pode ser afetada por diversos fatores; entre eles destacam-se: a etapa de colheita mecanizada, por causarem injúrias mecânicas as sementes (CUNHA et al., 2009), o grau de umidade das sementes durante a etapa da colheita (TERASAWA et al., 2009) e o fator genético de cada genótipo (POPINIGIS, 1985).

Para sementes de soja, a colheita é a fase mais crítica de todo o processo de produção, pois pode ocasionar perdas na qualidade das sementes (FRANÇA NETO et al., 2007), que podem refletir mais intensamente na deterioração das mesmas, se intensificando após período de armazenamento. Outro fator que contribui para a perda da qualidade das sementes é o grau de umidade no momento da colheita. Peske e Hamer (1997) constataram influencia do grau de umidade das sementes de soja no momento da colheita mecanizada, sendo que, sementes colhidas com graus de umidade mais elevados têm alterações diretamente sobre sua viabilidade e vigor. Neste sentido, à medida que o grau de umidade das sementes no momento da colheita atinge valores superiores a 18,0\%, há decréscimo na viabilidade das sementes (PESKE; HAMER, 1997). Já para aquelas colhidas com baixo grau de umidade, também há perdas na qualidade, pois estas estão mais sujeitas ao trincamento, resultando no rompimento dos tecidos e perda da viabilidade (CARVALHO; NAKAGAWA, 2000).

Alguns autores recomendam a colheita de sementes de soja, quando estas atingem umidade entre $12,0 \%$ a $14,0 \%$, pois esta faixa é a mais segura para evitar danificações na semente e perda de sua viabilidade e vigor (DALTRO et al., 2010; FRANÇA NETO et al., 2007). Porem, o grau de umidade das sementes quando estas estão na maturidade fisiológica ou prontas fisiologicamente para serem colhidas é de aproximadamente 50,0\% (LACERDA et al., 2003). Entretanto, neste momento as plantas ainda estão muito verdes, dificultando e até mesmo inviabilizando a etapa da colheita. Assim, as sementes permanecem no campo até atingirem graus de umidade mais reduzidos, ficando expostas a condições climáticas muitas vezes desfavoráveis para sua conservação, como chuvas, altas temperaturas, incidência de pragas e patógenos (GIURIZATTO et al., 2003).

No entanto, há informações na literatura que a lignificação do tegumento das sementes de soja, confere menor perda em sua qualidade no momento da colheita e protegendo a parede celulósica do ataque de microrganismos, conferindo melhor qualidade as mesmas (OBANDO-FLOR et al., 2004). Essas informações foram confirmadas por França Neto et al. (2007), ao observarem que a utilização de genótipos de soja com mais de 5,00\% de teor de lignina no tegumento das sementes favorece a produção de sementes de melhor qualidade, pois a lignina, além de proporcionar maior resistência das sementes às injúrias mecânicas, confere maior tolerância à deterioração por umidade; e menor velocidade de hidratação das sementes (SANTOS et al., 2007).

Sabe-se que, a qualidade das sementes interfere no estabelecimento adequado do estande de plantas, refletindo diretamente sobre a produtividade da cultura (ANDREOLI et al., 2002; MARCOS FILHO, 2005). Neste sentido, torna-se fundamental confrontar a qualidade fisiológica das sementes, levando-se em consideração a adoção de genótipos de comportamento distintos, em função da sensibilidade a deterioração no campo, condicionado pelo teor de lignina presente no tegumento das sementes. Outro aspecto relevante é avaliar a influência da colheita mecanizada destas sementes, colhidas com graus de umidade distintos, 
e também verificando essas condições em situação de colheita manual das sementes; uma vez que a semente caracteriza-se como uma das bases para uma produção rentável ao produtor.

Nesse sentido, o objetivo dessa pesquisa foi determinar as alterações fisiológicas de sementes de soja colhidas de forma manual e mecânica com diferentes teores de água.

\section{Material e Métodos}

As sementes para o estudo foram produzidas em área experimental do Departamento de Produção Vegetal, da Escola Superior de Agricultura Luiz de Queiroz, da Universidade de São Paulo, em Piracicaba (latitude: $22^{\circ} 42^{\prime} 30^{\prime \prime} \mathrm{S}$ e $47^{\circ} 38^{\prime} 00^{\prime}$ ' O; altitude: 546 m e clima Cwa "Köppen": temperado úmido com inverno seco e verão quente), no Estado de São Paulo, na safra 2007/2008. Foram utilizadas para o estudo sementes de soja de duas cultivares: FTS Águia e Embrapa 48; que foram avaliadas inicialmente à semeadura, quanto aos teores de lignina do tegumento, segundo procedimento descrito por Alvarez et al. (1997). As sementes da cultivar FTS Águia tinham 8,08\% de lignina no tegumento e foram consideradas como mais resistentes à injúrias mecânicas, portanto de maior qualidade, em relação às sementes da cultivar Embrapa 48, que tinham 6,96\% de lignina.

Para o experimento em campo foram instaladas 18 parcelas para cada cultivar em estudo. Para cada cultivar, nove parcelas foram destinadas a colheita manual e as outras nove a colheita mecânica; sendo estabelecidos para cada tipo de colheita (manual e mecânica), três graus de umidade das sementes, a saber: $18,0 \% ; 15,0 \%$ e $12,0 \%$, com três repetições cada. As parcelas (7,0 m x 4,5 m) foram constituídas por dez linhas, com sete metros de comprimento, espaçadas de 0,45 m; a área útil de colheita de cada parcela correspondeu às seis linhas centrais e os cinco metros centrais de cada linha. O preparo do solo, a adubação, a irrigação e o controle fitossanitário e de plantas invasoras foram efetuados conforme as recomendações para a cultura da soja indicadas por Embrapa (2006).

Para determinar o momento da colheita, foram realizadas coletas diárias das sementes de soja, duas vezes ao dia (pela manhã e no período da tarde), em pontos aleatórios da área de produção, iniciadas quando as plantas de soja atingiram o estádio de desenvolvimento R7 (início da maturação) até R8 (maturação plena), segundo descrição fenológica proposta por Fehr e Caviness (1980). O teor de água das sementes foi determinado conforme especificado nas Regras para Análise de Sementes (BRASIL, 2009), por meio do método de estufa.

As sementes foram colhidas de forma manual e mecânica em três épocas distintas. Para realização da colheita manual, utilizou-se tesoura de poda, sendo as plantas cortadas em sua haste principal rente ao solo, e depois abrigadas em sacos de ráfia em polipropileno. Posteriormente as plantas cortadas foram encaminhadas para galpão ventilado e trilhadas manualmente imediatamente após a colheita. Para a colheita mecânica foi empregada a colhedora para áreas experimentais, marca Hege ${ }^{\circledR}$, Modelo 140, com a rotação do cilindro regulada em $510 \mathrm{rpm}$ e velocidade da máquina de, aproximadamente, 4 quilômetros por hora (EMBRAPA, 2006).

No momento da colheita, as sementes da cultivar Embrapa 48 colhidas manualmente apresentavam $18,4 \% ; 14,4 \%$ e $11,6 \%$ de água e as colhidas mecanicamente $20,2 \% ; 15,9 \%$ e $12,0 \%$; para a cultivar FTS Águia as sementes colhidas manualmente apresentavam $17,5 \% ; 14,2 \%$ e $11,4 \%$ de água e as colhidas mecanicamente 17,9\%; 14,7\% e $12,7 \%$.

Imediatamente após cada colheita, as sementes foram avaliadas quanto ao grau de umidade e foram secadas em estufa de circulação forçada de ar, adotando-se $32{ }^{\circ} \mathrm{C}$ como temperatura máxima da massa de sementes, até que as sementes atingissem $11,0 \%$ de água. Após a etapa da secagem, as sementes foram acondicionadas em sacos de papel do tipo 
Kraft e armazenadas em ambiente controlado, com temperatura de $20{ }^{\circ} \mathrm{C}$ e $45 \%$ de Umidade Relativa do ar, durante todo o período experimental, visando minimizar a intensidade de deterioração.

As seguintes avaliações foram realizadas imediatamente após a secagem e aos seis meses de armazenamento:

1) Determinação do grau de umidade: avaliado pelo método de estufa a $105 \pm 3{ }^{\circ} \mathrm{C}$, por 24 horas, com duas repetições para cada tratamento (BRASIL, 2009). Os resultados foram expressos em porcentagem média, na base úmida.

2) Teste de germinação: para cada repetição vinda de campo, foram utilizadas quatro subamostras de 50 sementes cada, distribuídas em rolos de papel toalha, umedecido com quantidade de água equivalente a 2,5 vezes a massa do substrato seco e mantidas em germinador, a $25{ }^{\circ} \mathrm{C}$. A contagem de plântulas normais foi realizada aos cinco e oito dias após a semeadura (BRASIL, 2009). Os resultados foram expressos em porcentagem de plântulas normais.

3)Teste detetrazólio: empregado o procedimento descrito por França Neto, Krzyzanowski e Costa (1998). Para cada repetição vinda de campo, foram utilizadas duas subamostras com 50 sementes cada. As amostras foram pré-condicionadas entre papel toalha umedecido, com quantidade de água equivalente a 2,5 vezes a massa do papel, durante $16 \mathrm{~h}$ a $25^{\circ} \mathrm{C}$. Em seguida, as sementes foram colocadas em recipientes de plástico e mantidas submersas em solução $0,075 \%$ de cloreto de 2,3,5 trifenil tetrazólio, a $40{ }^{\circ} \mathrm{C}$ no escuro, por 150 minutos. Decorrido esse período, as sementes foram lavadas em água corrente e analisadas uma a uma, computando-se como número de sementes viáveis (viabilidade) as incluídas nas classes de sementes 1 a 5; e como potencialmente vigorosas (vigor) as incluídas nas classes de sementes 1 a 3 . Os resultados foram expressos em porcentagem de sementes viáveis e vigorosas.
4) Teste de envelhecimento acelerado: foi utilizado o método descrito por Marcos Filho (1999), com o uso de caixas plásticas que contém em seu interior uma bandeja de tela de alumínio, onde foram distribuídas as sementes formando camada única, o conjunto foi mantido a $41{ }^{\circ} \mathrm{C}$ e 100\% de Umidade Relativa do ar, durante 48 horas. Em seguida foi instalado o teste de germinação, conforme item 2 , com avaliação aos cinco dias após a semeadura. Após condução do teste foi determinado o grau de umidade das sementes, conforme item 1. Os resultados foram expressos em porcentagem de plântulas normais.

5) Teste de emergência de plântula: para cada repetição vinda de campo, foram utilizadas três subamostras de 50 sementes, distribuídas em bandejas, em sulcos de $20 \mathrm{~cm}$ de comprimento e 2 $\mathrm{cm}$ de profundidade, utilizando o substrato areia, mantidas em casa de vegetação, sob temperatura ambiente e com irrigação a cada três dias. Foram realizadas contagens diárias das plântulas emersas até a estabilização, considerando-se como plântula emergida, o estádio de emergência VE (FEHR; CAVINESS, 1980). Com os dados foram calculados a porcentagem de plântulas emersas e o índice de velocidade de emergência de plântula conforme proposto por Maguire (1962).

Os dados obtidos em cada teste foram analisados de acordo com delineamento inteiramente casualizado, separadamente para cada cultivar e teste conduzido. Os resultados dos testes foram transformados em arco sen $\sqrt{ } \mathrm{x} / 100$, empregando o sistema computacional Statistical Analysis System (SAS, 2008) versão 9.1 para computadores. As médias foram comparadas pelo teste de Tukey $(\mathrm{p} \leq$ $0,05)$.

\section{Resultados e Discussão}

As sementes pertencentes a cada cultivar utilizada na pesquisa apresentaram diferenças no teor de lignina no tegumento (Embrapa 48: 6,96\% e FTS 
Águia: 8,08\%); esse fato se faz importante, pois de acordo com França Neto et al. (2007) e Obando-Flor et al. (2004), sementes de soja com teor de lignina no tegumento acima de $5,00 \%$ são caracterizadas como resistentes aos danos mecânicos, menos sensíveis ao ataque de microrganismos e portanto de maior qualidade. Neste sentido, os resultados fornecidos na pesquisa, embasam o comportamento distinto das cultivares mediante as alterações na qualidade fisiológica das sementes; considerando- se a variação pelo tipo de colheita (manual ou mecânica) e pelo grau de umidade das sementes.

Quando se analisou os dados referentes ao grau de umidade das sementes, das cultivares Embrapa 48 e FTS Águia (Tabela 1), antes e após o teste de envelhecimento acelerado, os resultados indicaram, para os tratamentos analisados, valores similares após a secagem e o armazenamento. A uniformidade do teor de água das sementes é fundamental para a padronização das avaliações e obtenção de resultados consistentes (MARCOS FILHO, 1999).

Tabela 1. Resultados da determinação do grau de umidade antes a após o teste de envelhecimento acelerado (E.A.), em sementes de soja, das cultivares Embrapa 48 e FTS Águia, realizados após a colheita (inicial) e aos seis meses de armazenamento (após armazenamento).

\begin{tabular}{|c|c|c|c|c|}
\hline Cultivares & \multicolumn{2}{|c|}{ Avaliação: após colheita } & \multicolumn{2}{|c|}{ Avaliação: após armazenamento } \\
\hline Embrapa 48 & Antes E.A. & Após E.A. & Antes E.A. & Após E.A. \\
\hline & \multicolumn{4}{|c|}{------------------- \% grau de umidade ------------------ } \\
\hline C.manual $(18,4 \%)$ & $10,6 \mathrm{a}$ & $25,5 \mathrm{a}$ & $8,3 \mathrm{a}$ & $23,1 \mathrm{a}$ \\
\hline C.manual $(14,4 \%)$ & $10,7 \mathrm{a}$ & $25,9 \mathrm{a}$ & $9,0 \mathrm{a}$ & $24,3 \mathrm{a}$ \\
\hline C.manual $(11,6 \%)$ & $12,4 \mathrm{a}$ & $26,1 \mathrm{a}$ & $11,2 \mathrm{a}$ & $23,2 \mathrm{a}$ \\
\hline C.mecânica $(20,2 \%)$ & $11,1 \mathrm{a}$ & $26,6 \mathrm{a}$ & 7,9 a & $23,3 \mathrm{a}$ \\
\hline C.mecânica $(15,9 \%)$ & $11,0 \mathrm{a}$ & $25,9 \mathrm{a}$ & $8,7 \mathrm{a}$ & $24,5 \mathrm{a}$ \\
\hline C.mecânica $(12,0 \%)$ & $10,4 \mathrm{a}$ & $25,6 \mathrm{a}$ & $8,7 \mathrm{a}$ & $24,9 \mathrm{a}$ \\
\hline C.V. $(\%)$ & 3,1 & 3 & 6,5 & 3,8 \\
\hline \multirow[t]{2}{*}{ FTS Águia } & Antes E.A. & Após E.A. & Antes E.A. & Após E.A. \\
\hline & \multicolumn{4}{|c|}{------------------- \% grau de umidade ------------------- } \\
\hline C.manual $(17,5 \%)$ & $11,5 \mathrm{a}$ & $25,9 \mathrm{a}$ & $10,4 \mathrm{a}$ & $22,5 \mathrm{a}$ \\
\hline C.manual $(14,2 \%)$ & $12,4 \mathrm{a}$ & $25,5 \mathrm{a}$ & $11,4 \mathrm{a}$ & $22,7 \mathrm{a}$ \\
\hline C.manual $(11,4 \%)$ & $10,9 \mathrm{a}$ & $25,5 \mathrm{a}$ & $9,3 \mathrm{a}$ & $23,3 \mathrm{a}$ \\
\hline C.mecânica $(17,9 \%)$ & $10,7 \mathrm{a}$ & $25,8 \mathrm{a}$ & $9,7 \mathrm{a}$ & $23,3 \mathrm{a}$ \\
\hline C.mecânica $(14,7 \%)$ & $10,6 \mathrm{a}$ & $25,2 \mathrm{a}$ & $9,5 \mathrm{a}$ & $24,0 \mathrm{a}$ \\
\hline C.mecânica $(12,7 \%)$ & $10,5 \mathrm{a}$ & $22,2 \mathrm{a}$ & $8,6 \mathrm{a}$ & $22,0 \mathrm{a}$ \\
\hline C.V. $(\%)$ & 3,4 & 1,9 & 5,4 & 4,3 \\
\hline
\end{tabular}

Médias seguidas de mesma letra na coluna não diferem entre si pelo teste de Tukey $\mathrm{p} \leq 0,05$.

Ao avaliar a germinação das sementes da cultivar Embrapa 48 (Tabela 2), não houve variação estatística para as sementes colhidas manualmente com teor de água na faixa de $14,4 \%$ e 18,4\%, independente da época de avaliação. Quando analisada as sementes colhidas à máquina, não verifica-se variação na germinação das sementes, quando estas foram colhidas com 15,9\% e 12,0\% de água. Sabe-se que sementes de soja colhidas com teor de água baixo, estão mais propensas ao dano por trincamento e rompimento dos tecidos, comprometendo assim a qualidade do material (CARVALHO; NAKAGAWA, 2000). Porém, observa-se pelos resultados apresentados que, apenas as sementes colhidas à máquina com menor teor de água (12,0\%), se adéquam ao padrão mínimo de germinação para comercialização de sementes de soja, de $80 \%$. Quando se verifica o comportamento 
das sementes colhidas à máquina com o maior grau de umidade (20,2\%), os resultados obtidos pelo teste de germinação (Tabela 2) indicam que esta condição não garantiu a qualidade das sementes. Resultados similares foram obtidos por Peske e Hamer (1997).

Em relação à germinação das sementes da cultivar FTS Águia (Tabela 3) não foram verificadas diferenças significativas $(\mathrm{p} \leq 0,05)$ entre as colheitas manual ou mecânica, em todas as faixas de umidade das sementes. É importante salientar que na referida pesquisa ambas as cultivares possuem mais de 5,00\% de teor de lignina no tegumento, que segundo Santos et al. (2007), exercem influência direta na qualidade das sementes, pois tornam as sementes menos sensíveis aos danos mecânicos e a incidência por patógenos, em função da integridade do tegumento. No entanto, quando o padrão mínimo de germinação é levado em consideração, foram os tratamentos colhidos manualmente com 14,2 e $17,5 \%$ de água e os colhidos à máquina com 12,7 e $14,7 \%$ de água, que mantiveram a germinação mínima (80\%), para sementes de soja, estabelecidos pela Instrução Normativa n. ${ }^{\circ} 25$ (MAPA, 2005), mesmo após período de armazenamento. Quanto às sementes que não mantiveram a germinação mínima após o período de armazenamento, este decréscimo é um processo degenerativo natural que as sementes encontram em diversas condições ambientais a que estão condicionadas, como oscilações na umidade relativa do ar e temperatura (GUARCONI et al., 2001).

Tabela 2. Resultados da avaliação de sementes de soja, cultivar Embrapa 48, colheitas manual (C.manual) ou mecânica (C.mecânica) com diferentes teores de água, pelos testes de germinação, emergência de plântula e de tetrazólio (viabilidade), realizados logo após a colheita (inicial) e aos seis meses de armazenamento (6 meses).

\begin{tabular}{|c|c|c|c|c|c|c|}
\hline \multirow{2}{*}{ Tratamentos } & \multicolumn{2}{|c|}{ Germinação } & \multicolumn{2}{|c|}{ Emergência de plântula } & \multicolumn{2}{|c|}{ Viabilidade (TZ) } \\
\hline & Inicial & 6 meses & Inicial & 6 meses & Inicial & 6 meses \\
\hline & & & & & & \\
\hline C.manual $(18,4 \%)$ & $76 \mathrm{a}$ & $68 \mathrm{a}$ & $91 \mathrm{a}$ & $90 \mathrm{a}$ & $98 \mathrm{a}$ & $91 \mathrm{a}$ \\
\hline C.manual $(14,4 \%)$ & $77 \mathrm{a}$ & $72 \mathrm{a}$ & 89 a & $92 \mathrm{a}$ & $94 \mathrm{ab}$ & $90 \mathrm{a}$ \\
\hline C.manual $(11,6 \%)$ & $68 \mathrm{ab}$ & $55 \mathrm{~b}$ & 89 a & $88 \mathrm{a}$ & 93 bc & $81 \mathrm{a}$ \\
\hline C.mecânica $(20,2 \%)$ & $50 \mathrm{~b}$ & $50 \mathrm{~b}$ & $78 \mathrm{a}$ & $82 \mathrm{a}$ & $85 \mathrm{c}$ & $83 \mathrm{a}$ \\
\hline C.mecânica $(15,9 \%)$ & $76 \mathrm{a}$ & $55 \mathrm{~b}$ & $86 \mathrm{a}$ & $89 \mathrm{a}$ & $87 \mathrm{bc}$ & $82 \mathrm{a}$ \\
\hline C.mecânica $(12,0 \%)$ & $85 \mathrm{a}$ & $54 \mathrm{~b}$ & $89 \mathrm{a}$ & $87 \mathrm{a}$ & 92 bc & $86 \mathrm{a}$ \\
\hline $\mathrm{CV}(\%)$ & 9,4 & 2,6 & 9,4 & 5,1 & 3,9 & 6,5 \\
\hline
\end{tabular}

Médias seguidas de mesma letra na coluna não diferem entre si pelo teste de Tukey $p \leq 0,05$.

Os resultados do teste de emergência de plântula, para as sementes das cultivares Embrapa $48 \mathrm{e}$ FTS Águia (Tabelas 2 e 3), apresentaram médias superiores às observadas no teste de germinação e não diferiram entre si estatisticamente. No referido teste, verificou-se que a colheita manual, independente da cultivar utilizada (Tabelas 2 e 3), indicou valores na germinação das sementes entre $88 \%$ a $99 \%$, ou seja, acima do padrão mínimo de comercialização, de $80 \%$. Resultados semelhantes foram obtidos por Braccini et al. (1994), que verificaram também valores significativamente superiores de viabilidade das sementes, de diferentes genótipos de soja, no teste de emergência de plântula em relação aos obtidos no de germinação. Segundo França Neto e Henning (1984), este resultado está relacionado à infecção das sementes por Phomopsis spp., visto que a presença desse fungo está restrita, na maioria dos casos, apenas ao tegumento, causando variações nos resultados obtidos entre os testes de germinação e o conduzido na areia. 
Tabela 3. Resultados da avaliação de sementes de soja, cultivar FTS Águia, colheitas manual (C.manual) ou mecânica (C.mecânica) com diferentes teores de água, testes de germinação, emergência de plântula e de tetrazólio (viabilidade), realizados logo após a colheita (inicial) e aos seis meses de armazenamento (6 meses).

\begin{tabular}{|c|c|c|c|c|c|c|}
\hline \multirow{2}{*}{ Tratamentos } & \multicolumn{2}{|c|}{ Germinação } & \multicolumn{2}{|c|}{ Emergência de plântula } & \multicolumn{2}{|c|}{ Viabilidade (TZ) } \\
\hline & Inicial & 6 meses & Inicial & 6 meses & Inicial & 6 meses \\
\hline C.manual $(17,5 \%)$ & $92 \mathrm{a}$ & $88 \mathrm{a}$ & 99 a & $97 \mathrm{a}$ & $97 \mathrm{a}$ & $95 \mathrm{a}$ \\
\hline C.manual $(14,2 \%)$ & $85 \mathrm{a}$ & $81 \mathrm{a}$ & $97 \mathrm{a}$ & $97 \mathrm{a}$ & $95 \mathrm{a}$ & $95 \mathrm{a}$ \\
\hline C.manual $(11,4 \%)$ & $83 \mathrm{a}$ & $75 \mathrm{a}$ & $97 \mathrm{a}$ & $95 \mathrm{a}$ & $94 \mathrm{a}$ & $93 \mathrm{a}$ \\
\hline C.mecânica (17,9\%) & $83 \mathrm{a}$ & $78 \mathrm{a}$ & $93 \mathrm{a}$ & $94 \mathrm{a}$ & $93 \mathrm{a}$ & $91 \mathrm{a}$ \\
\hline C.mecânica $(14,7 \%)$ & $88 \mathrm{a}$ & $84 \mathrm{a}$ & $99 \mathrm{a}$ & $92 \mathrm{a}$ & $95 \mathrm{a}$ & $92 \mathrm{a}$ \\
\hline C.mecânica $(12,7 \%)$ & $89 \mathrm{a}$ & $85 \mathrm{a}$ & $99 \mathrm{a}$ & $95 \mathrm{a}$ & $94 \mathrm{a}$ & $91 \mathrm{a}$ \\
\hline CV $(\%)$ & 7,8 & 6,7 & 7,0 & 4,5 & 7,0 & 5,1 \\
\hline
\end{tabular}

Médias seguidas de mesma letra na coluna não diferem entre si pelo teste de Tukey $\mathrm{p} \leq 0,05$.

A viabilidade das sementes da cultivar Embrapa 48 (teor de lignina de 6,96\%) pelo teste de tetrazólio, Tabela 2, quando se realizou a colheita manual, com grau de umidade das sementes na faixa entre $11,6 \%$ a 18,4\% de água, não houve alterações fisiológicas na qualidade das sementes após o período de armazenamento; o mesmo ocorreu quando as sementes foram colhidas mecanicamente com $12,0 \%$ a $15,9 \%$ de água, na avaliação inicial e após período de armazenamento. Para as sementes da cultivar FTS Águia (teor de lignina de 8,08\%), tanto as sementes colhidas manualmente, entre $11,4 \%$ a $17,5 \%$, como as colhidas a máquina, entre $12,7 \%$ a $17,9 \%$, foi mantida a viabilidade, sem alterações na qualidade fisiológica, independente da época de avaliação (logo após a colheita e aos seis meses de armazenamento).

Com relação ao vigor das sementes da cultivar Embrapa 48 (Tabela 4), obtido pelo teste de tetrazólio, os resultados indicaram que sementes colhidas manualmente entre $14,4 \%$ e $18,4 \%$ de água, mantiveram sua qualidade fisiológica; sendo que após a colheita (avaliação inicial), o vigor das sementes se mantiveram nos parâmetros estabelecidos por França Neto, Krzyzanowski e Costa (1998), classificando as sementes como de vigor muito alto e após o armazenamento, o vigor das sementes teve um declínio, enquadrando-o como sementes viáveis e de vigor médio. Para as sementes colhidas mecanicamente, a condição mais adequada para manutenção da qualidade fisiológica das sementes foi nas faixas de umidade entre $15,9 \%$ a $20,2 \%$, pois se obteve médio vigor das sementes (FRANÇA NETO; KRZYZANOWSKI; COSTA, 1998); permitindo sua utilização em função da sua viabilidade, mesmo após seis meses de armazenamento (Tabela 2). Tais resultados demonstram o potencial do teste de tetrazólio para indicar diferenças de vigor nas sementes de soja (COSTA et al., 2009).

$\mathrm{O}$ vigor das sementes da cultivar FTS Águia (Tabela 5), colhidas manualmente se mantiveram nos padrões estabelecidos por França Neto; Krzyzanowski e Costa (1998), os quais indicaram sementes de vigor muito alto, aquelas com valores acima de $84 \%$ e as de vigor alto, aquelas entre $75 \%$ a $84 \%$, estes resultados permaneceram mesmo após o período de armazenamento. Para as sementes colhidas à máquina, a análise do vigor, classificou as sementes pertencentes às faixas com: 14,7\% e 17,9\% de água, como as de vigor alto (FRANÇA NETO; KRZYZANOWSKI; COSTA, 1998) às colhidas com $12,7 \%$ de água em vigor médio (FRANÇA NETO; KRZYZANOWSKI; COSTA, 1998); e mesmo após o período de armazenamento o vigor das sementes conservaram-se com vigor médio, apresentando viabilidade acima de 91\% (Tabela 3). Estes resultados, confirmando observações feitas 
por Hamer e Peske (1997), os quais observaram que sementes de soja colhidas entre $14,0 \%$ a $18,0 \%$ de água, mantém a qualidade fisiológica das sementes.

As sementes da cultivar Embrapa 48 (Tabela 4), submetidas ao teste de envelhecimento acelerado, não indicaram diferenças significativas $(p \leq 0,05)$, entre as colheitas manual e mecânica, independente da época de avaliação. No entanto, verifica-se na análise inicial das sementes, que a colheita mecânica com umidade das sementes de 20,2\%, indicou resultados de germinação, abaixo dos estabelecidos para a comercialização de sementes de soja, de $80 \%$; sendo este valor reduzido a $60 \%$ após período de armazenamento. O comportamento das sementes da cultivar FTS Águia colhidas manualmente (Tabela 5), depois de submetidas ao teste de envelhecimento acelerado, não indicou alterações significativas na germinação das mesmas (variação de 93\% a 97\%). Mesmo após o período de armazenamento (Tabela
5), sementes da cultivar FTS Águia colhidas manualmente com $11,4 \%$ e $17,5 \%$ mantiveram-se com germinação acima de $80 \%$. Para as sementes colhidas à máquina, na faixa de $17,9 \%$ de água, os resultados apresentaram germinação superior; embora após período de armazenamento a qualidade fisiológica para as sementes colhidas nas faixas de umidade entre $12,7 \%$ a $14,7 \%$ se igualaram quanto a germinação, com as sementes colhidas com 17,9\% de água. O teste de envelhecimento acelerado aplicado em sementes de soja é um dos mais confiáveis para distinção de alterações fisiológicas (MARCOS FILHO; NOVEMBRE, CHAMMA, 2001). O grau de umidade das sementes, para ambas cultivares, após o teste de envelhecimento acelerado (Tabela 1), confirma a confiabilidade dos resultados apresentados, uma vez que os valores foram uniformes para todos os tratamentos em estudo; estando de acordo com os valores referenciais citados por Marcos Filho (1999).

Tabela 4. Resultados da avaliação de sementes de soja, cultivar Embrapa 48, colheitas manual (C.manual) ou mecânica (C.mecânica) com diferentes teores de água, pelos testes de tetrazólio (vigor), envelhecimento acelerado (E.A.) e índice de velocidade de emergência (I.V.E.), logo após a colheita (inicial) e aos seis meses de armazenamento (6 meses).

\begin{tabular}{|c|c|c|c|c|c|c|}
\hline \multirow{2}{*}{ Tratamentos } & \multicolumn{2}{|c|}{ Tetrazólio (Vigor) } & \multicolumn{2}{|c|}{ E.A. } & \multicolumn{2}{|c|}{ I.V.E. } \\
\hline & Inicial & 6 meses & Inicial & 6 meses & Inicial & 6 meses \\
\hline & & & - & & $\ldots$ & \\
\hline C.manual $(18,4 \%)$ & $<91$ a $>$ & $<68 \mathrm{a}>$ & $<89$ a $>$ & $<75 \mathrm{a}>$ & $<7,32$ a $>$ & $7,06 \mathrm{ab}$ \\
\hline C.manual $(14,4 \%)$ & $<89 \mathrm{a}>$ & $<72 \mathrm{a}>$ & $<88$ a $>$ & $<79 a>$ & $<7,28$ a $>$ & $7,30 \mathrm{a}$ \\
\hline C.manual $(11,6 \%)$ & $73 \mathrm{~b}$ & $<55 \mathrm{a}>$ & $<83$ a $>$ & $<80$ a $>$ & $<7,07 \mathrm{a}>$ & $6,83 a b$ \\
\hline C.mecânica $(20,2 \%)$ & $74 \mathrm{~b}$ & $<50 \mathrm{a}>$ & $<76$ a $>$ & $<60$ a $>$ & $<6,26$ a $>$ & $6,28 \mathrm{~b}$ \\
\hline C.mecânica $(15,9 \%)$ & $68 \mathrm{~b}$ & $<55 \mathrm{a}>$ & $<86 \mathrm{a}>$ & $<69$ a $>$ & $<6,64$ a $>$ & $6,98 \mathrm{ab}$ \\
\hline C.mecânica $(12,0 \%)$ & $74 \mathrm{~b}$ & $<54 \mathrm{a}>$ & $<83$ a $>$ & $<79 \mathrm{a}>$ & $<7,35$ a $>$ & $7,05 \mathrm{ab}$ \\
\hline CV $(\%)$ & 5,0 & 10,4 & 6,7 & 9,2 & 4,6 & 6,3 \\
\hline
\end{tabular}

Médias seguidas de mesma letra na coluna não diferem entre si pelo teste de Tukey $p \leq 0,05$.

O índice de velocidade de emergência (Tabela 4) para as sementes da cultivar Embrapa 48, colhidas manualmente não permitiram distinguir diferenças estatísticas $(p \leq 0,05)$ entre as faixas de umidade de $11,6 \%$ a $18,4 \%$; embora após o período de armazenamento o índice de velocidade tenha diminuído, a agilidade de emergência foi entre
$6,83 \%$ a $7,06 \%$, sendo um resultado satisfatório, levando em consideração as condições adversas das quais as sementes foram submetidas, uma vez que estas foram condicionadas a temperatura ambiente e a irrigação artificial a cada três dias. Quando avaliou-se o índice de velocidade de emergência para as sementes colhidas à máquina (Tabela 
4), os melhores índices foram para as sementes colhidas com graus de umidade entre 12,0\% a $15,9 \%$, pois as mesmas mantiveram valores satisfatórios (entre 6,64\% a 7,35\%), mesmo após o período de armazenamento. No geral, observouse que os decréscimos nos índices de velocidade de emergência são devido à sequência natural de alterações fisiológicas iniciadas na semente logo após a maturidade fisiológica, culminando com a diminuição na viabilidade das sementes (MARCOS FILHO, 2005); sendo mais expressivo após o período de armazenamento.

Tabela 5. Resultados da avaliação de sementes de soja, cultivar FTS Águia, colheitas manual (C.manual) ou mecânica (C.mecânica) com diferentes teores de água, pelos testes de tetrazólio (vigor) e de envelhecimento acelerado (E.A.) e índice de velocidade de emergência (I.V.E.), logo após a colheita (inicial) e aos seis meses de armazenamento (6 meses).

\begin{tabular}{|c|c|c|c|c|c|c|}
\hline \multirow{2}{*}{ Tratamentos } & \multicolumn{2}{|c|}{ Tetrazólio (Vigor) } & \multicolumn{2}{|c|}{ E.A. } & \multicolumn{2}{|c|}{ I.V.E. } \\
\hline & Inicial & 6 meses & Inicial & 6 meses & Inicial & 6 meses \\
\hline & & & 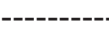 & & ------- & \\
\hline C.manual $(17,5 \%)$ & $<91$ a $>$ & $<81$ a $>$ & $<97 \mathrm{a}>$ & $<92 \mathrm{a}>$ & $<8,22$ a $>$ & $<7,94$ a $>$ \\
\hline C.manual $(14,2 \%)$ & $86 a b$ & $<82$ a $>$ & $93 a b$ & $<77$ a $>$ & $<8,03$ a $>$ & $<7,88$ a $>$ \\
\hline C.manual $(11,4 \%)$ & $83 a b$ & $<81$ a $>$ & $95 \mathrm{ab}$ & $<85 \mathrm{a}>$ & $<7,90$ a $>$ & $<7,59$ a $>$ \\
\hline C.mecânica $(17,9)$ & $76 a b$ & $<71$ a $>$ & $90 \mathrm{ab}$ & $<87 \mathrm{a}>$ & $<7,65$ a $>$ & $<7,57 \mathrm{a}>$ \\
\hline C.mecânica $(14,7 \%)$ & $77 \mathrm{ab}$ & $<70$ a $>$ & $88 \mathrm{~b}$ & $<87 \mathrm{a}>$ & $<7,91$ a $>$ & $<6,89$ a $>$ \\
\hline C.mecânica $(12,7 \%)$ & $74 \mathrm{~b}$ & $<69 \mathrm{a}>$ & $88 \mathrm{~b}$ & $<82 \mathrm{a}>$ & $<8,15$ a $>$ & $<7,44$ a $>$ \\
\hline CV $(\%)$ & 7,1 & 7,8 & 4,6 & 10,3 & 1,7 & 6,4 \\
\hline
\end{tabular}

Médias seguidas de mesma letra na coluna não diferem entre si pelo teste de Tukey $\mathrm{p} \leq 0,05$.

O índice de velocidade de emergência para as sementes da cultivar FTS Águia (Tabela 5), não apresentou alterações estatísticas entre os graus de umidade das sementes no momento das colheitas manual ou mecânica. Segundo Vieira, Rouverson e Roberval (2006), a avaliação de distinções na qualidade fisiológica de sementes de soja pelo índice de velocidade de emergência pode não ser eficiente.

\section{Conclusões}

Sementes de soja, com variação do teor de lignina no tegumento de $6,96 \%$ a $8,08 \%$, colhidas manualmente na faixa de umidade entre $11,4 \%$ a $18,4 \%$, não tiveram alterações em sua qualidade fisiológica, mantendo sua viabilidade mesmo após seis meses de armazenamento.
Recomenda-se, a colheita mecanizada de sementes de soja, com teores de lignina no tegumento de $6,96 \%$ e $8,08 \%$, quando estas atingem grau de umidade entre $12,0 \%$ a $15,9 \%$, mantendo sua qualidade fisiológica mesmo após seis meses de armazenamento.

\section{Agradecimento}

À Fundação de Amparo a Pesquisa do Estado de São Paulo (FAPESP), pelo auxílio financeiro.

\section{Referências}

ALVAREZ, P. J. C.; KRZYZANOWSKI, F. C.; MANDARINO, J. M. G.; FRANÇA NETO, J. B. Relationship between soybean seed coat lignin content and resistance to mechanical damage. Seed Science and Technology, Zürich, v. 25, n. 2, p. 209-214, 1997. 
ANDREOLI, C.; ANDRADE, R. V.; ZAMORA, S. A.; GORDON, M. Influência da germinação da semente e da densidade de semeadura no estabelecimento do estande e na produtividade de milho. Revista Brasileira de Sementes, Brasília, v. 24, n. 2, p. 1-5, 2002.

BRACCINI, A. L.; REIS, M. S.; SEDIYAMA, C. S.; SEDIYAMA, T. Avaliação da qualidade fisiológica e sanitária da semente de genótipos de soja (Glycine max (L.) Merril) com diferentes graus de impermeabilidade do tegumento. Revista Brasileira de Sementes, Brasília, v. 16, n. 2, p. 195-200, 1994.

BRASIL. Ministério da Agricultura, Pecuária e Abastecimento. Secretaria de Defesa Agropecuária. Regras para análise de sementes. Brasília: Mapa/ACS, 2009. 399 p.

CARVAlHO, N. M.; NAKAGAWA, J. Sementes: ciência, tecnologia e produção. 4. ed. Jaboticabal: FUNEP, 2000. 588 p.

COMPANHIA NACIONAL DE ABASTECIMENTO - CONAB. Acompanhamento de safra brasileira: grãos, quarto levantamento. Brasília: Conab, 2011. 41 p. (Companhia Nacional de Abastecimento). Disponível em: $\quad<$ http://www.conab.gov.br/OlalaCMS/uploads/ arquivos /11_01_06_08_41_56_boletim_graos_4o_lev safra_2010_2011.pdf $>$. Acesso em: 5 set. 2011.

COSTA,N.P.;FRANÇANETO,J.B.;KRZYZANOWSKI, F. C.; HENNING, A. A. Metodologia alternativa para o teste de tetrazólio em semente de soja. Londrina: EMBRAPA, CNPSo, 2009. 8 p. (Circular técnica, 39).

CUNHA, J. P. A. R.; OLIVEIRA, P.; SANTOS, C. M.; MION, R. L. Qualidade das sementes de soja após a colheita com dois tipos de colhedora e dois períodos de armazenamento. Ciência Rural, Santa Maria, v. 39, n. 5, p. 1420-1425, 2009.

DALTRO, E. M. F.; ALBUQUERQUE, M. C. F.; FRANÇA NETO, J. B.; GUIMARÃES, S. C.; GAZZIERO, D. L. P.; HENNING, A. A. Aplicação de dessecantes em pré-colheita: efeito na qualidade fisiológica de sementes de soja. Revista Brasileira de Sementes, Brasília, v. 32, n. 1, p. 111-122, 2010.

EMPRESA BRASILEIRA DE PESQUISA AGROPECUÁRIA - EMBRAPA. Tecnologias de produção de soja - Região central do Brasil - 2007. Londrina: EMBRAPA, CNPSo, 2006. 225 p. (Sistemas de Produção, n. 11).

FEHR, W. E.; CAVINESS, C. E. Stages of soybean development. Ames: Iowa State University, 1980. 11 p. (Cooperative Extension Service - Special Report, 80).
FRANÇA NETO, J. B.; HENNING, A. A. Qualidade fisiológica e sanitária de sementes de soja. Londrina: EMBRAPA, CNPSo, 1984. 39 p. (Circular técnica, 9).

FRANÇA NETO, J. B.; KRZYZANOWSKI, F. C.; COSTA, N. P. O teste de tetrazólio em sementes de soja. Londrina: EMBRAPA, CNPSo, 1998. 72 p. (Documentos, 116).

FRANÇA NETO, J. B.; KRZYZANOWSKI, F. C.; PÁDUA, G. P.; COSTA, N. P.; HENNING, A. A. Tecnologia da produção de sementes de soja de alta qualidade. Londrina: EMBRAPA, CNPSo, 2007. 12 p. (Circular técnica, 40).

GIURIZATTO, M. I. K.; SOUZA, L. C. F.; ROBAINA, A. D.; GONÇALVES, M. C. Efeito da época de colheita e da espessura do tegumento sobre a viabilidade e o vigor de sementes de soja. Ciência e Agrotecnologia, Lavras, v. 27, n. 4, p. 771-779, 2003.

GUARCONI, R. C.; DURAES, F. O. M.; MAGALHAES, P. C.; SILVA, R. F. Efeito do armazenamento na qualidade fisiológica das sementes de populações de milho cultivadas sob estresses hídrico e mineral. Pesquisa Agropecuária Brasileira, Brasília, v. 36, n. 12, p. 14791484, 2001.

HAMER, E.; PESKE, S. T. Colheita de sementes de soja com alto grau de umidade. I - Qualidade física. Revista Brasileira de Sementes, Brasília, v. 19, n. 1, p. 106-110, 1997.

LACERDA, A. L. S.; LAZARINI, E.; SÁ, M. E.; VALÉRIO FILHO, W. V. Armazenamento de sementes de soja dessecadas e avaliação da qualidade fisiológica, bioquímica e sanitária. Revista Brasileira de Sementes, Brasília, v. 25, n. 2, p. 97-105, 2003.

MAGUIRE, J. D. Speed of germination-aid in relation evaluation for seedling emergence vigor. Crop Science, Madison, v. 2, n. 2, p. 176-177, 1962.

MINISTÉRIO DA AGRICULTURA, PECUÁRIA E DO ABASTECIMENTO - MAPA. Instrução Normativa n. 25, de 16 de dezembro de 2005. Padrões de identidade e qualidade para produção e comercialização de sementes. Anexo IX - Padrões para produção e comercialização de sementes de soja. 2005. Disponível em: <http://www. apassul.com.br/arquivo/ in25novospadroes/anexo9-soja. pdf $>$. Acesso em: 13 mar. 2011.

MARCOS FILHO, J. Fisiologia de sementes de plantas cultivadas. Piracicaba: FEALQ, 2005. 495 p.

Teste de envelhecimento acelerado. In: KRZYZANOWSKI, F. C.; VIEIRA, R. D.; FRANÇA NETO, J. B. (Ed.). Vigor de sementes: conceitos e testes. Londrina: ABRATES, 1999. cap. 3, p. 1-24. 
MARCOS FILHO, J.; NOVEMBRE, A. D. C.; CHAMMA, H. M. C. P. Testes de envelhecimento acelerado e de deterioração controlada para avaliação do vigor de sementes de soja. Scientia Agrícola, Piracicaba, v. 58, n. 2 , p. $421-426,2001$.

OBANDO-FLOR, E. P.; CICERO, S. M.; FRANÇA NETO, J. B.; KRZYZANOWSKI, F. C. Avaliação de danos mecânicos em sementes de soja por meio da análise de imagens. Revista Brasileira de Sementes, Brasília, v. 26, n. 1, p. 68-76, 2004.

PESKE, S. T.; HAMER, E. Colheita de sementes de soja com alto grau de umidade. II - Qualidade fisiológica. Revista Brasileira de Sementes, Brasília, v. 19, n. 1, p. 66-70, 1997.

POPINIGIS, F. Fisiologia de semente. Brasília: AGIPLAN, 1985. 289 p.
SANTOS, E. L.; PÓLA, J. N.; BARROS, A. S. R.; PRETE, C. E. C. Qualidade fisiológica e composição química das sementes de soja com variação na cor do tegumento. Revista Brasileira de Sementes, Pelotas, v. 29, n. 1, p. 20-26, 2007.

SAS Institute. SAS/STAT ${ }^{\circledR}$. User's guide: statistics. versão 9.1. Cary: SAS Institute, 2008. (Software).

TERASAWA, J. M.; PANOBIANCO, M.; POSSAMAI, E.; KOEHLER, H. S. Antecipação da colheita na qualidade fisiológica de sementes de soja. Bragantia, Campinas, v. 68, n. 3, p. 765-773, 2009.

VIEIRA, B. G. T. L.; ROUVERSON, P. S.; ROBERVAL, D. V. Qualidade física e fisiológica de semente de soja colhida com sistema de trilha axial sob diferentes velocidades de operação e rotações do cilindro trilhador. Revista Engenharia Agrícola, Jaboticabal, v. 26, n. 2, p. 478-482, 2006. 
